\title{
Chemical Fingerprint by HPLC-DAD-ESI-MS, GC-MS Analysis and Anti-Oxidant Activity of Manasamitra Vatakam: A Herbomineral Formulation
}

\author{
Srikalyani $\mathbf{V}^{1}$, llango $\mathrm{K}^{1,2, *}$
}

Srikalyani $\mathrm{V}^{1}$, Ilango $\mathrm{K}^{1,2, *}$

'Division of Analytical Chemistry, Interdisciplinary Institute of Indian System of Medicine (IIISM), SRM Institute of Science and Technology, Kattankulathur-603 203, Kancheepuram (Dt), Tamil Nadu, INDIA. ${ }^{2}$ Department of Pharmaceutical Chemistry, SRM College of Pharmacy, SRM Institute of Science and Technology, Kattankulathur-603 203, Kancheepuram (Dt), Tamil Nadu, INDIA.

\section{*Correspondence}

\section{llango K}

Division of Analytical Chemistry, Interdisciplinary Institute of Indian System of Medicine (IIISM); Department of Pharmaceutical Chemistry, SRM College of Pharmacy, SRM Institute of Science and Technology, Kattankulathur-603 203, Kancheepuram (Dt), Tamil Nadu, INDIA.

E-mail: ilangok67@gmail.com

History

- Submission Date: 02-09-2019;

- Review completed: 10-10-2019;

- Accepted Date: 28-11-2019.

DOI : $10.5530 /$ pj.2020.12.18

Article Available online http://www.phcogj.com/v12/i1

Copyright

(c) 2020 Phcogj.Com. This is an openaccess article distributed under the terms of the Creative Commons Attribution 4.0 International license.

\begin{abstract}
Background: Manasamitra Vatakam is a classical ayurvedic herbo mineral formulation used for the treatment of neurodegerative properties and epileptic disorders. The wide range mixture of herbal extracts and minerals were used in the formulation. Aim: The aim of the study implies in performing the chemo-profiling, chromatographic fingerprint analysis by HPLC-DAD-ESI-MS for the selected formulations of Manasamitra Vatakam followed by the identification of bioactive compounds by Gas Chromatography - Mass Spectrometric (GC-MS) analysis, to evaluate the diffusion and dilution methods for the determination of anti-bacterial activity in the methanolic extracts of Manasamitra Vatakam (MMV). Materials and Methods: The antibacterial activity was performed by both diffusion and dilution methods whereas the antioxidant activity was performed by free radical scavenging of 2,2-diphenyl-1-picrylhydrazy and hydrogen peroxide scavenging assay method. Results: The estimation of bioactive constituents showed positive results by qualitative analysis. Antibacterial activity of MMV was evaluated against two-gram positive Staphylococcus aureus and Bacillus cereus, two gram negative Escherichia coli and Klebsiella pneumonia by disk diffusion $\left(0.078-10 \mu \mathrm{g} \mathrm{mL}^{-1}\right)$, broth dilution $\left(0.078-10 \mu \mathrm{g} \mathrm{mL}^{-1}\right)$ and broth micro dilution method $\left(0.39-50 \mu \mathrm{g} \mathrm{mL}^{-1}\right)$ respectively. The bioactive constituents were analysed by GC-MS analysis for the methanolic extract of the formulation. Conclusion: To conclude, the formulation was found abundant with phenolic and flavonoid compounds by HPLC-ESI-MS analysis, the bioactive compounds identified are responsible for the anti-bacterial activity. The broth microdilution method performed by resazurin method was observed as the fast screening, sensitive and accurate method for the quantitative determination of antibacterial activity.
\end{abstract}

Key words: Classical formulation, Phytochemicals, MIC, Diffusion and dilution methods, Heavy metals.

\section{INTRODUCTION}

Globally, India is the largest producer of medicinal herbs used for enormous aliments in day to day practise. In the traditional medicinal systems, the whole plant is used as the alternative and complementary therapy. ${ }^{1}$ Medicinal plants have been the mainstream of traditional herbal medicines worldwide since the antiquity to date. ${ }^{2}$ About $1 / 4^{\text {rth }}$ of the pharmaceutical industries have structural modifications of natural products for the advancement of drug discovery and development. The non-nutrient compounds or the bioactive constituents referred to as "phytochemicals" are responsible against various microbial infections and hence the study of natural products is known as "Phytochemistry". Even, the pharmacological activity of the crude extract is determined by the nature of phyto constituents present in the plant species and these compounds are responsible for the potential activity are known as "Secondary metabolites" like alkaloids, flavonoids, isoprenoids, saponins exerts antioxidant, steroidal activity, modulation of hormones and detoxification of enzymes and anti-cancer properties. Hence, plants are the major source of mankind throughout the history. ${ }^{4,5}$ With the rise in the clinical toxicity, the use of ayurvedic formulation is enhancing significantly over the decade. ${ }^{6}$ The standardization of botanicals for the specific markers was confirmed with the fingerprinting analysis. Ayurveda is considered as "Mother of healing", is the integral part of the traditional medicine claims to aid the various metabolic and chronic disorders by enhances the longevity.

Manasamitra Vatakam (MMV) is a herbomineral formulation, a Classical traditional medicine from the antique Ayurvedic formulations cited in Sahasrayogam, potentially used for memory impairment, neuroprotective activity and manic illness. ${ }^{8}$ MMV contains a composite mixture of 55 plant species of varying therapeutic activities like anxiolytic, anti-depressant, Antioxidant and antiepileptic activities. ${ }^{9}$ The minerals present in MMV are Pravala pishti, Tamrachuda Padika, Rajata Bhasma, Swarna Bhasma, Mrigashringa Bhasma, Makshika Bhasma, Mukta Pishti, Loha Bhasma and Shilajat. $70-80 \%$ of the nutrient consumptions were proven to be obtained from the vegetable crops in the form herbal supplements claims to contain the heavy metal and the trace elements in it. The macro and

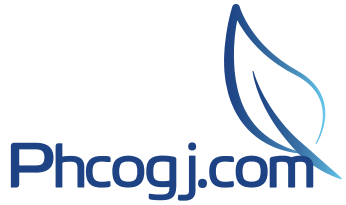

Cite this article: Srikalyani V, Ilango K. Chemical Fingerprint by HPLC-DAD-ESI-MS, GC-MS Analysis and Anti-Oxidant Activity of Manasamitra Vatakam: A Herbomineral Formulation. Pharmacog J. 2020;12(1):115-23. 
microelements are used for various biochemical processes in the human body reveals to have a significant effect on combating various ailments. In parallel to which, with the increase in adverse drug events from the synthetic drugs many of the populations finds the herbal drugs are of safe and intoxic with lesser amount side effects. But, upon the regular usage of these herbal formulations results in the nephrotoxicity because of the contaminants, heavy metals and adulterants used.

Chemo-profiling and marker analysis plays a critical role in the herbal drug for ensuring the therapeutic efficacy, pharmacokinetic profile. ${ }^{10,11}$ The profiling and fingerprinting of phytoconstituents explores the plant analysis better and is the best alternative for the classical analytical methodology. Nevertheless, it helps to differentiate the species are of authentic or adulterated by its origin and allows for the proper discrimination between the species or the herbal medicines. LC-MS fingerprinting analysis can be laid as a platform for the additional testing to identify the fingerprinting analysis as it emphasizes on the systematic characterization of herbal compositions. No methodology has stated for the qualitative or quantitative estimation of the MMV for the quality control of the herbs, hence from the quality aspects of the classical formulation the fingerprinting analysis was performed to be the emerging need for its identification. The HPLC-DAD-ESIMS analysis was performed for the fingerprinting analysis and further confirmation of the constituents were determined qualitatively. GCMS is the versatile analytical technique which is unsuited to rapid high sensitivity analysis of specific compounds, represents the mass of specific particle $(\mathrm{Da})$ to number $(\mathrm{z})$ of electrostatic changes (e). ${ }^{12}$ The inborn error of metabolism in new-born are detectable, isotopic labelling of metabolites helps in metabolic activity. In traditional medicine, GC-MS is the feasible technique for the analysis of the liposoluble compounds like volatile or essential oils. ${ }^{13}$

The Minimum inhibitory concentration (MIC) is the minimum (lowest) concentration of a test compound that will inhibit the growth of a bacterial strain. It can be done in several methods like micro dilution or macro dilution test, extended break point sensitivity test and e-strip test methods. Conventionally, this is determined using a series of doubling dilutions of the antibiotic in liquid culture medium, to produce a range of concentrations in test tubes (macro dilution) or in a microtiter tray (micro dilution). After inoculation of the test strain into each antibiotic concentration, bacterial growth is determined by visible turbidity after $18-24 \mathrm{~h}$ of incubation. The MIC is the lowest concentration of compound with no visible bacterial growth. ${ }^{14,15}$

In the present study, four different marketed formulations of MMV were chosen, and analyzed for the estimation of bioactive constituents, heavy metal analysis for the determination of elemental and trace analysis, HPLC-DAD-ESI-MS fingerprinting analysis. Based on the results, comparative profiling was studied for all the four formulations of MMV, of all the formulations the formulation found to be comparatively better was subjected to GC-MS analysis to study the possible volatile compounds present and also the evaluation of antibacterial activity was studied by both the diffusion and dilution techniques in the herbo mineral formulation.

\section{MATERIALS AND METHODS}

\section{Materials}

All the chemicals of analytical grade were procured and used for the analysis. HPLC grade Methanol 99.9\% (Merck Specialties' Pvt. Ltd., Mumbai, India), Milli-Q water (Milli-Q10 TS, Millipore water Purification system, Merck) was used. Formulations A, B, C and D of MMV were prescribed by Ayurvedic Physician and procured from Ayurvedic pharmacy. Quercetin, glucose, gallic acid, ursolic acid, diosgenin were purchased form $\mathrm{M} / \mathrm{s}$ Natural remedies, Bangalore.
Cefotaxime susceptibility test discs (SD040-1VL) were procured from HIMEDIA lab Pvt. Ltd.

\section{Sample preparation}

A pooled mix of tablets of twenty was finely weighed and powdered. $1 \mathrm{~g}$ of powdered mix was transferred into a $10 \mathrm{~mL}$ standard flask. Sample extraction was exerted by adding $5 \mathrm{~mL}$ of methanol followed by sonication for about $30 \mathrm{~min}$ and made to the mark with the diluent. The sample matrix prepared was then subjected to prior filtration with Whatmann filter paper and followed by $0.2 \mu \mathrm{m}$ membrane filter. The filtered solution was used to perform the HPLC-DAD-ESI-MS and GCMS analysis.

\section{Estimation of bioactive constituents}

Bioactive compounds often termed as secondary metabolites are essential for eliciting the pharmacological effects. Besides the primary metabolites, secondary metabolites are the compounds regarded as "biological side tracks" functioning of the plant. Irrespective of the pharmacological activity they themselves help in shielding the plant as a whole i.e., flavonoids protect against free radicals during photosynthesis, terpenoids attract pollinators and inhibit the competing plants, and alkaloids rid the phytoalexins and herbivore animals. However, exceptionally few plants are highly poisonous due to the increased concentration of secondary metabolites. The determination of the bioactive contents i.e., alkaloids, flavonoids, glucoside, phenolic, saponins, sterol saponins, sterols and terpenoids were estimated in all the four formulations of MMV..$^{16-20}$

\section{In vitro antioxidant activity}

The Antioxidant activity was performed by DPPH (2,2-diphenyl1picrylhyrazyl) free radical scavenging activity. $0.1 \mathrm{mM}$ of DPPH was prepared using methanol as vehicle from which $1 \mathrm{~mL}$ was added to the formulation extract diluted to various concentrations. The aliquots were incubated in the dark at room temperature for $30 \mathrm{~min}$ and the absorbance was recorded at $517 \mathrm{~nm}$, where ascorbic acid was kept as positive control. ${ }^{21}$ The samples were performed in triplicated and expressed as \% incubation percentage. The IC50 value was calculated using Graph pad prism.

\section{Elemental analysis}

The glassware and Teflon tube used for digestion were soaked in dilute nitric acid and rinsed with Milli-Q-water. All the standard solutions were made by diluting $1000 \mathrm{mg} / \mathrm{L}$ of stock solutions (Merck). For the estimation of $\mathrm{Hg}$, As and Se 5\%v/v HCL was used for both standards and sample preparations, Whereas Milli-Q-water was used as diluent for $\mathrm{Zn}, \mathrm{Cr}, \mathrm{Ni}, \mathrm{Cu}, \mathrm{Fe}, \mathrm{Na}, \mathrm{Pb}$ and $\mathrm{Cd}$ standards and sample analysis. ${ }^{22}$ Elemental analysis was carried out by using atomic absorption spectroscopy (AAS) system (AA 7000 AAS, Lab India Instruments Pvt Ltd).

The sample was subjected to digestion in microwave digestor as per EPA Method 3052, ${ }^{23} 1996$ with slight modification in the methodology. Briefly, $0.5 \mathrm{~g}$ of the formulation in powder form was taken in a digestor holder of $100 \mathrm{~mL}$ capacity to which $5 \mathrm{~mL}$ of concentrated $\mathrm{HCl}$ and 5 $\mathrm{mL}$ of $\mathrm{HNO}_{3}$ was added, mixed well and digested for a period of 30 min. The mixture was then transferred to a $100 \mathrm{~mL}$ volumetric flask, diluted with small volumes of Milli-Q-water to avoid splashes of acid matrix, filtered with Whatmann No.1 and then made up to mark with Milli-Q-water. The Sample obtained was taken up for analysis and also a blank digest was conducted in the similar way. Flame absorption method (FAM) was used to determine the concentration of $\mathrm{Zn}, \mathrm{Cr}, \mathrm{Ni}$, $\mathrm{Cu}, \mathrm{Fe}, \mathrm{Na}, \mathrm{Ca}, \mathrm{Pb}$ and $\mathrm{Cd}$ using air-acetylene as carrier gas. $\mathrm{Hg}$, As and Se concentration was estimated by hydride generation method (HGAAS) equipped with AAA7000. 5\% v/v HCl was used as carrier liquid 
$2 \%$ sodium borohydride $\left(\mathrm{NaBH}_{4}\right)$ in $0.5 \%(\mathrm{w} / \mathrm{v})$ sodium hydroxide $(\mathrm{NaOH})$ was used as reducing agent. Milli-Q-water and $5 \% \mathrm{v} / \mathrm{v} \mathrm{HCl}$ was used as diluents for FAM and HG-AAS method respectively.

Instrument calibration was performed with a blank solution made to autozero followed by standardization with different working standards of different calibration sets. Standard samples were analysed prior to the samples to plot the calibration curve. The analysis was carried out in triplicate and the absorbance was measured.

\section{INSTRUMENTATION AND CHROMATOGRAPHIC CONDITIONS}

\section{HPLC-DAD-ESI-MS analysis}

The HPLC system comprises of a Shimadzu binary solvent delivery module (LC10ADVP), SPD M20A PDA detector and manual Rheodyne injector with the loop capacity of $0.02 \mathrm{~mL}$ loop volume and column oven CT0-20A on the whole controlled by the communication module CBM-20A. The chromatographic separation was achieved using Phenomenex $\mathrm{C}_{18}$ column $(25 \mathrm{~cm} \times 4.6 \mathrm{~mm} ; 5 \mu)$ and the solvent system of water-formic acid (A; 100:0.1\% v/v) and methanol (B) at 45:55 v/v with an isocratic flow of $0.8 \mathrm{~mL} / \mathrm{min}$. The detection was set at $254 \mathrm{~nm} .^{24-26}$.

The separation was made on an (G1) LC-MS 2020 system equipped with single quadrupole mass spectrometer with electrospray ionization ESI $(+)$ source with the positive ionization mode. The temperature was set at $280^{\circ} \mathrm{C}$ and $320^{\circ} \mathrm{C}$ for curved desolvation line (CDL) and heat block. The interface parameters as; nitrogen gas was used to assist nebulization with a flow rate of $1.5 \mathrm{~mL} / \mathrm{min}$. The drying gas flow was maintained at $15 \mathrm{~L} / \mathrm{min}$.

\section{GC-MS analysis}

For the identification of the chemical compounds, the methanolic extract was subjected to analysis on Agilent GC-MS system (GC 7890B equipped with Agilent 5977A MSD mass detector) using HP_5 Phenyl Methyl Silox $\left(60^{\circ} \mathrm{C}-325^{\circ} \mathrm{C}\right) 30 \mathrm{~m} \times 250 \mathrm{~mm} \times 0.2 \mu \mathrm{m}$ capillary as stationary phase. The oven temperature programming employed was with the initial temperature of $80^{\circ} \mathrm{C}$ for $1 \mathrm{~min}$, raised for $70^{\circ} \mathrm{C}$ linearly to $220^{\circ} \mathrm{C}$ and held for $5 \mathrm{~min}$, followed with the linear raise of $10^{\circ} \mathrm{C} / \mathrm{min}$ to $290^{\circ} \mathrm{C}$ and held for $10 \mathrm{~min}$. the injector port was maintained at $290^{\circ} \mathrm{C}$, helium gas was used as carrier gas with a flow rate of $1.2 \mathrm{~mL} \mathrm{~min}^{-1}$. Samples were given through split less mode of $1 \mu \mathrm{L}$ injection volume i.e., in the ratio of $1: 10$. The ionization voltage of $70 \mathrm{ev}$ and ion source temperature was kept at $280^{\circ} \mathrm{C}$. The injection was performed by split mode with a split ratio of 10: 1 . Solvent delay time was set for $3 \mathrm{~min}$ for all samples generated by different methods. MSWS V 8.0 workstation was used to process data. Interpretation on mass spectrum of GC-MS was done using the database of in-built libraries like NIST 8 (National Institute of Standards and Technology) and WILEY 9 having more than 62,000 patterns. $^{27}$

\section{Bacterial strain and growth conditions}

The test bacterial strains include the gram positive Staphylococcus aureus and Bacillus cereus, gram negative Escherichia coli and Klebsiella pneumonia. The test microorganisms were obtained from MTCC. The bacteria were revived and maintained in nutrient broth at $35^{\circ} \mathrm{C}$ in a shaking incubator.

\section{Disk diffusion method}

To perform the diffusion assay method, nutrient agar medium and petri plates were sterilized in autoclave and followed by solidification of the medium in the laminar air flow hood. The assay for the antibacterial activity of each culture was diluted with agar medium to $10^{-5}$ to $10^{-6}$ CFU $\mathrm{mL}^{-1}$. $1 \mathrm{~mL}$ of each bacterial suspension was uniformly spread on the growth medium in the petri plate to which sterile paper disk $6 \mathrm{~mm}$ were placed on the agar plate and were impregnated with $10 \mathrm{ul}$ of the sample. The plates were incubated for $24 \mathrm{~h}$. Disk impregnated with the antibiotic cefotaxime $30 \mu \mathrm{g} /$ disc serves as positive control and replicate for each concentration was performed. ${ }^{28}$

\section{Broth dilution assay}

$5 \mathrm{~mL}$ of sterile nutrient broth medium was taken into the test tubes for the proper growth of the medium. Serial dilutions in the nutrient broth were performed using the sample concentration of $10 \mathrm{mg} / \mathrm{mL}$ to $0.078 \mathrm{mg} / \mathrm{mL}$ to which loop full of microbial suspension was inoculated. All the inoculated tubes were incubated at the temperature of $37^{\circ} \mathrm{C}$ for $24 \mathrm{~h}$. Following the incubation of the broth tubes, were examined for the presence of microbial growth. The antibacterial activity in terms of MIC was the lowest concentration of the suspension where no viability was observed after $24 \mathrm{~h}$ of incubation. The MIC was recorded by taking the optical density values of each concentration of the test inoculum at which the bacteria failed to grow or the lowest concentration which inhibits the growth of bacteria from the cell suspension after the incubation of $37^{\circ} \mathrm{C}$ for $24 \mathrm{~h}$. The broth tubes were interpreted by measuring the OD values using UV-Spectrophotometer. The entire test was performed in duplicate. ${ }^{29}$

\section{Broth microdilution assay}

The resazurin based dilution method is the most appropriate method for the determination of MIC values for the anti-bacterial activity, as the possibility was enhanced for two-fold dilution of the anti-bacterial agent with the smaller volumes using 96-well microtituration plate. Staphylococcus aureus and Bacillus cereus (Gram-positive), Escherichia coli and Klebsiella pneumonia (Gram-negative) were grown on Nutrient agar by streak plate technique. After $48 \mathrm{~h}$, the individual colonies were picked and inoculated in the nutrient broth. Both the cultures were monitored for growth using a UV-1800 spectrophotometer (Shimadzu, Japan) after $24 \mathrm{~h}$ at a wavelength of $600 \mathrm{~nm}$ to obtain a final OD 1.0 These liquid cultures were used for further inoculation on 96-well microtituration plate. After well mixing without any agitation the 96well microtituration plate was cautiously incubated under $35 \pm 2^{\circ} \mathrm{C}$ for $20 \mathrm{~h}$ (Table 3). Eventually, the resazurin solution was prepared with the concentration of $6 \mathrm{mg} \mathrm{mL}^{-1}$ with sterile water as vehicle and the mixture was vortexed to ensure for the homogenous solution.

\section{RESULTS AND DISCUSSION}

\section{Phytochemical analysis}

Nonetheless, in all the four formulation A, B, C and D the composition of the plants is similar to as cited in Sahasrayogam, but the manufacturing and processing varies results in change in the presence of active constituents thereby results in the variation of the active principles present in the formulation. The methanolic extracts of the formulation $\mathrm{A}, \mathrm{B}, \mathrm{C}$ and $\mathrm{D}$ were subjected to bioactive estimations i.e. total alkaloid, flavonoid, glycoside, saponin, steroidal saponin and terpenoid content and the results were given in Figure 1 and depicted in the Table 1. From the phytochemical analysis, the determination of the major bioactive content was identified for all the formulations. Indeed, the formulation B has shown better availability of the bioactive contents followed by formulation D, A and C. The long-term utilization of the herbal medicines results in the deposition of the trace elements and the heavy metals in the human body resulting in the potential risk and it also depends on the daily dietary intake of the herbal medicines. Hence, the heavy metal and trace elemental analysis was performed and was present to be in varied amounts in all the formulations but Was found to be present in permissible limits and the results were listed in Table 2. From, the HPLC chromatograms of all the four formulations were submitted to LC-MS analysis. 
Table 1: Estimation of phytochemical constituents in Manasamitra Vatakam of various formulations.

\begin{tabular}{|c|c|c|c|c|}
\hline Quantitative parameters & Formulation $\mathrm{A}$ & Formulation B & Formulation C & Formulation D \\
\hline Alkaloid & $41.7 \pm 0.0009$ & $50.3 \pm 0.0024$ & $35.7 \pm 0.0007$ & $40.1 \pm 0.0003$ \\
\hline Flavonoid & $39.60 \pm 0.003$ & $47.40 \pm 0.003$ & $31.80 \pm 0.003$ & $45.2 \pm 0.003$ \\
\hline Glycoside & $10.7 \pm 0.0052$ & $23.1 \pm 0.0140$ & $6.6 \pm 0.0048$ & $12.9 \pm 0.0083$ \\
\hline Phenolic & $88.90 \pm 0.0014$ & $86.10 \pm 0.0031$ & $67.90 \pm 0.0010$ & $81.1 \pm 0.0017$ \\
\hline Saponin & $106.9 \pm 0.0032$ & $149.8 \pm 0.0038$ & $94.2 \pm 0.0026$ & $136.2 \pm 0.0056$ \\
\hline Sterol Saponin & $54.9 \pm 0.2117$ & $86.65 \pm 0.0510$ & $35.5 \pm 0.0328$ & $78.4 \pm 0.0746$ \\
\hline Terpenoid & $23.3 \pm 0.0091$ & $44.6 \pm 0.0129$ & $17.7 \pm 0.0212$ & $32.6 \pm 0.0146$ \\
\hline
\end{tabular}

Values are in mean $\pm S D, n=3$, phenolic equivalent to gallic acid, flavonoid equivalent to quercetin, glycoside equivalent to glucose, saponin, sterol saponin equivalent to diosgenin, terpenoid equivalent to ursolic acid.

Table 2: Concentration range $\left(\mathrm{mg} \mathrm{kg}^{-1}\right)$ of Heavy metal and trace elements present in MMV of various formulations.

\begin{tabular}{|c|c|c|c|c|c|}
\hline Elements & Formulation A & Formulation B & Formulation C & Formulation D & Limits \\
\hline Arsenic (As) & ND & ND & ND & ND & NMT 3 ppm \\
\hline Cadmium (Cd) & 0.027 & 0.032 & 0.040 & 0.039 & NMT $0.3 \mathrm{ppm}$ \\
\hline Mercury (Hg) & ND & ND & ND & ND & NMT $0.5 \mathrm{ppm}$ \\
\hline Lead $(\mathrm{Pb})$ & 1.231 & 1.744 & 1.979 & 2.681 & NMT $10 \mathrm{ppm}$ \\
\hline Calcium (Ca) & 2.385 & 1.184 & 2.210 & 1.557 & NMT 15ppm \\
\hline Copper (Cu) & 0.275 & 0.074 & 0.865 & 0.115 & NMT 40 ppm \\
\hline Iron $(\mathrm{Fe})$ & 12.25 & 9.48 & 21.177 & 12.074 & NMT 55 ppm \\
\hline Potassium (K) & 0.955 & 0.497 & 1.566 & 0.686 & NMT 20 ppm \\
\hline Selenium (Se) & ND & ND & ND & ND & NMT 2 ppm \\
\hline Sodium (Na) & 2.872 & 1.151 & 2.863 & 1.308 & NMT 10 ppm \\
\hline
\end{tabular}

\section{HPLC-DAD-ESI-MS fingerprinting analysis}

LC-MS fingerprinting analysis and sown in Figure 3; the process of selection includes the identification of common peaks, normalization of their retention times and determination of the mass value for all the common peaks present in the formulations. Out of all the peaks, 11 peaks are termed as common peaks as they are present in all the four formulations. ESI-MS was performed to further confirm the fingerprints of the peaks identified. Analysis was performed with both the positive and negative ionization modes. On comparison with the $\mathrm{m} / \mathrm{z}$ values all the peaks were unambiguously identified and were detected as Berberine, jatrorrhizine, curcumin, vitexin, rutin, quercetin, catechin, piperine, palmatine, naringenin, and ellagic acid respectively and the compounds were listed in the Table 3 . All the formulations have shown similar fingerprinting pattern and molecular mass. But, formulation B has showed higher peak abundance and the variations caused may be difference in the preparation, manufacturing, drying process and the storage conditions. Upon the comparative note, the order of phytochemical, heavy metal analysis and HPLC-DAD-ESIMS for the formulation Manasamitra Vatakam analysis was found to be Formulation $\mathrm{C}<$ Formulation $\mathrm{A}<$ Formulation $\mathrm{D}<$ Formulation $\mathrm{B}$.

\section{GC - MS analysis}

For the better understanding of the secondary metabolites present, formulation B was subjected to GC MS analysis and the GC MS chromatogram was depicted in Figure 4 and tabulated in Table 4. The results appertain to GC MS analysis for the methanolic extract of formulation B, Manasamitra Vatakam lead to the identification of numerous compounds. The compounds interpreted from the mass spectra are Cyclopropyl carbinol, Camphor (levo), Isobornyl alcohol, Safranal, Decanoic acid, Dodecanoic acid, Ascaridole epoxide, Cuminic acid, Undecanoic acid, 10-methyl-, methyl ester, Benzoic acid, Lauric acid, 4-Octadecenal, Diethyl Phthalate, $\alpha$ - Asarone, 2-Naphthalenemethanol, Ar-tumerone, $\beta$-bisabolol, $\beta$-Asarone, Methyl tetradecanoate, Isocalamendiol, 3,4,5-trimethoxyphenyl-2propanone, Tetradecanoic acid, Tricyclo(5.1.0.0(2,4))oct-5-ene-5propanoic acid, 3,3,8,8-tetramethyl-, $\beta$-Eudesmol, n-Pentadecanoic acid, 13-Heptadecyn-1-ol, 5(1H)-Azulenone, Phthalic acid, Phytol,

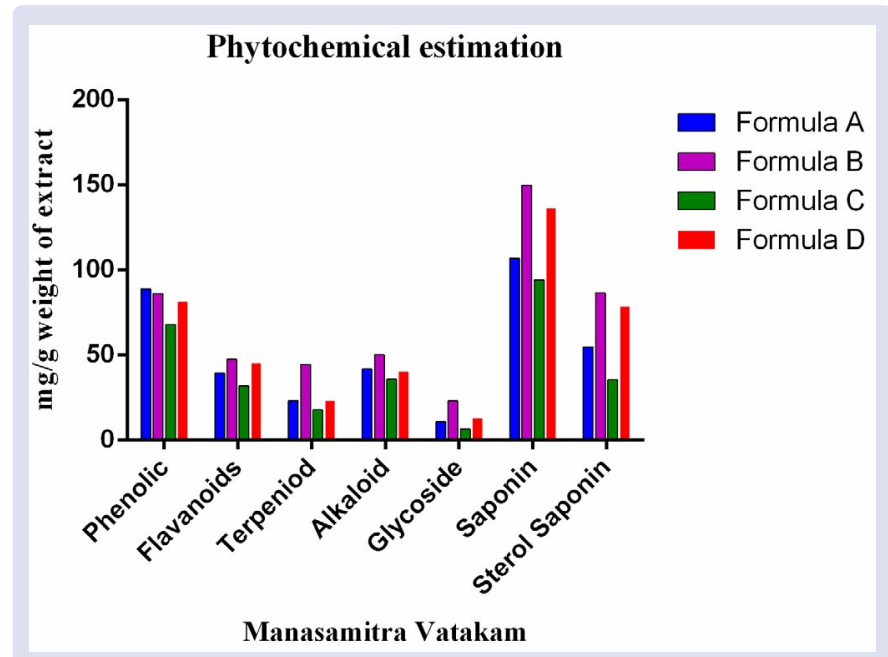

Figure 1: Comparative Profiling of Bioactive constituents in MMV of various formulations.

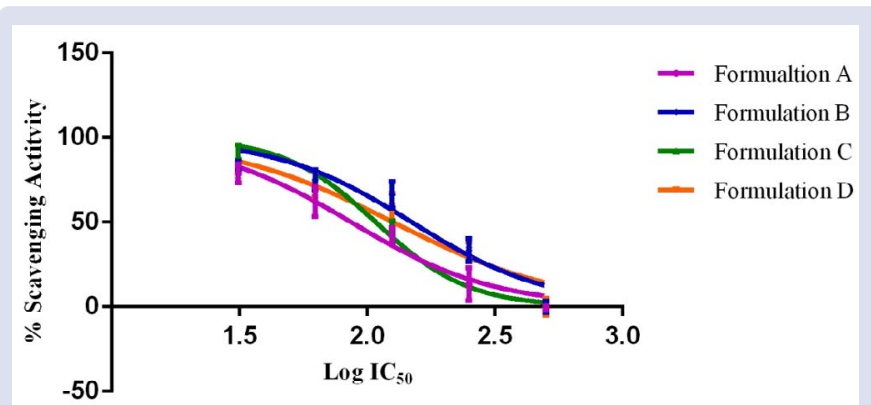

Figure 2: Antioxidant activity with DPPH assay.

a-Copaen-11-ol, Naphthalene, Benzenepropanoic acid, Eudesma5,11(13)-dien-8,12-olide, naphthalenone, n-Hexadecanoic acid, 18-Hydroxy-10-pentyl-11-oxa-1,5-dithia-spiro(5.13)nonadec-15-yn12-one, Hexadecanoic acid, Heptadecanoic acid, 9,12-Hexadecadienoic 

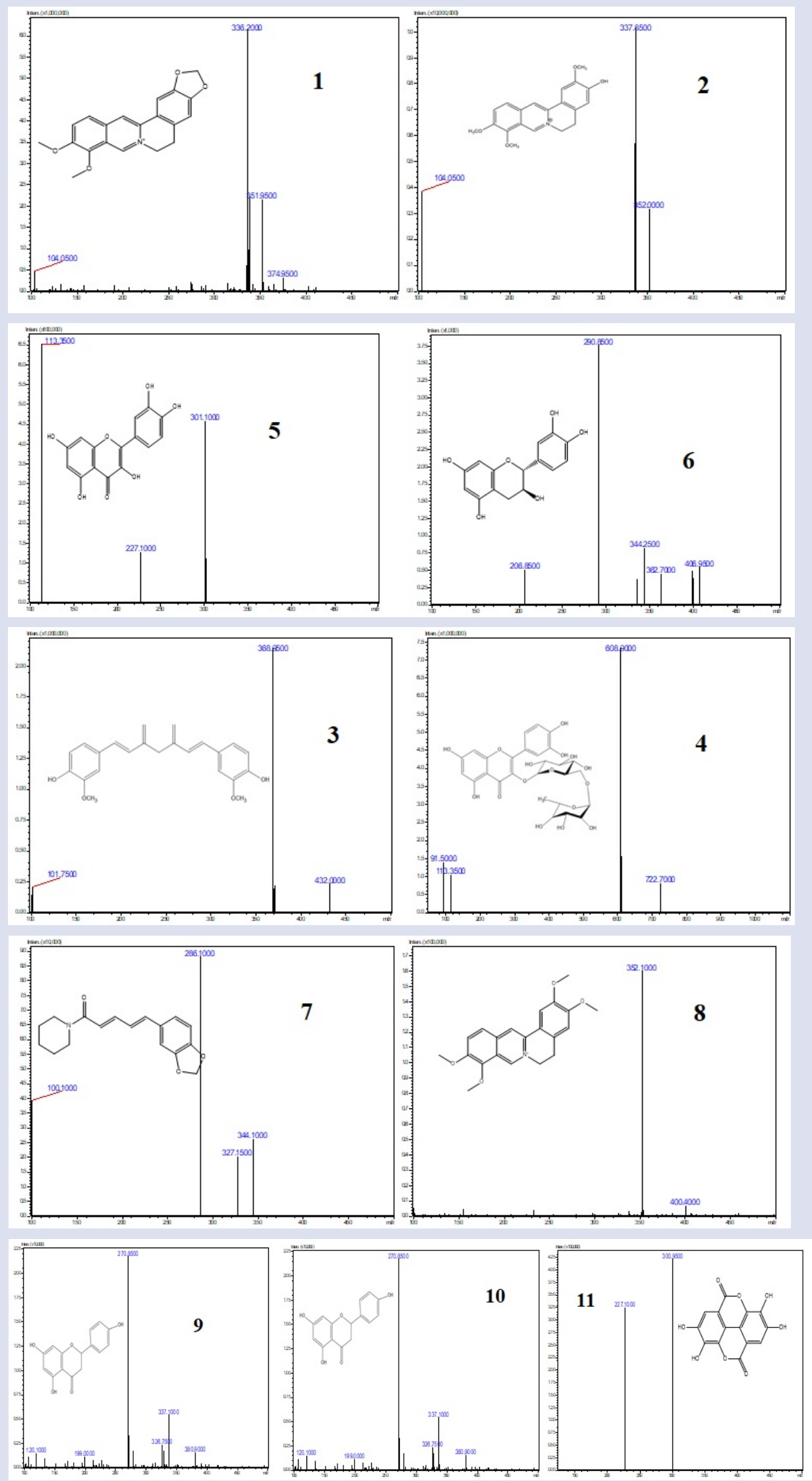

Figure 3: The characteristic compounds identified through mass spectrum by HPLC-DAD-ESI-MS analysis were bereberine (1), jatrorrhizine (2), curcumine (3), vitexin (4) rutin (5), quercetin (6), catechin (7), piperine (8), palmatine (9), naringenin (10) and ellagic acid (11). 


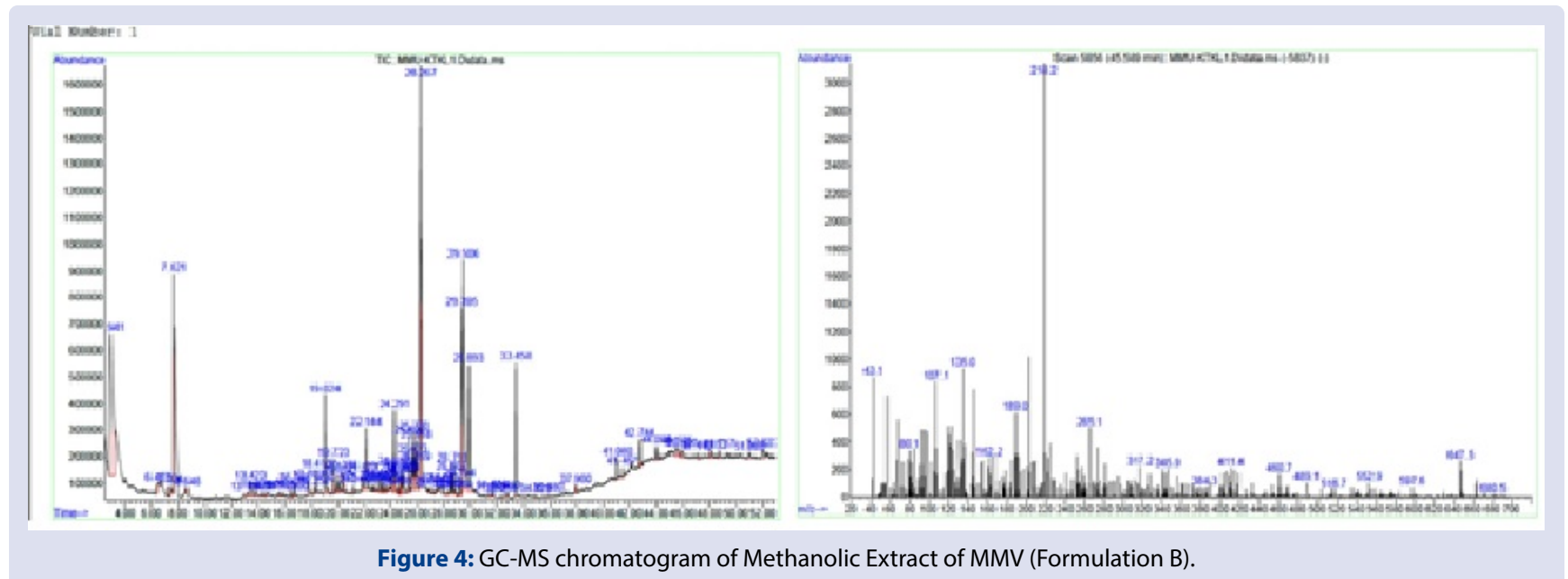

Table 3: Compounds identified in MMV by HPLC-DAD-ESI-MS.

\begin{tabular}{|c|c|c|c|c|c|c|c|}
\hline Peak No & Formulation A & Formulation B & Formulation C & Formulation D & $\mathrm{m} / \mathrm{z}$ value & $\begin{array}{c}\text { Molecular } \\
\text { Formula }\end{array}$ & Identification \\
\hline 01 & 3.107 & 3.201 & 3.112 & 3.136 & 336.05 & $\mathrm{C}_{20} \mathrm{H}_{18} \mathrm{NO}_{4}^{+}$ & Berberine \\
\hline 02 & 3.492 & 3.492 & 3. 499 & 3.480 & 338.92 & $\mathrm{C}_{20} \mathrm{H}_{20} \mathrm{NO}_{4}^{+}$ & Jatrorrhizine \\
\hline 03 & 3.607 & 3.605 & 3.606 & 3.597 & 367.05 & $\mathrm{C}_{21} \mathrm{H}_{20} \mathrm{O}_{6}$ & Curcumin \\
\hline 04 & 4.357 & 4.283 & 4.513 & 4.214 & 286.21 & $\mathrm{C}_{15} \mathrm{H}_{10} \mathrm{O}_{6}$ & Vitexin \\
\hline 05 & 5.140 & 5.157 & 5.103 & 5.113 & 609.21 & $\mathrm{C}_{27} \mathrm{H}_{30} \mathrm{O}_{16}$ & Rutin \\
\hline 06 & ND & 6.082 & ND & 6.124 & 301.26 & $\mathrm{C}_{15} \mathrm{H}_{10} \mathrm{O}_{7}$ & Quercetin \\
\hline 07 & 7.979 & 7.902 & 7.972 & 7.988 & 289.85 & $\mathrm{C}_{15} \mathrm{H}_{14} \mathrm{O}_{6}$ & Catechin \\
\hline 08 & 9.495 & 9.610 & 9.095 & ND & 286.10 & $\mathrm{C}_{17} \mathrm{H}_{19} \mathrm{NO}_{6}$ & Piperine \\
\hline 09 & 10.028 & 10.173 & ND & ND & 357.20 & $\mathrm{C}_{21} \mathrm{H}_{25} \mathrm{NO}_{4}$ & Palmatine \\
\hline 10 & 15.896 & 16.141 & 15.504 & 15.740 & 271.05 & $\mathrm{C}_{15} \mathrm{H}_{12} \mathrm{O}_{5}$ & Naringenin \\
\hline 11 & 17.266 & 17.337 & 17.455 & ND & 300.25 & $\mathrm{C}_{14} \mathrm{H}_{6} \mathrm{O}_{8}$ & Ellagic Acid \\
\hline
\end{tabular}

Table 4: Compounds identified in formulation B of MMV by GC-MS.

\begin{tabular}{|c|c|c|c|c|c|}
\hline Peak No & Retention time & Area & Molecular Formula & $\mathrm{m} / \mathrm{z}$ value & Compound name \\
\hline 1 & 7.621 & 4.624 & $\mathrm{C}_{10} \mathrm{H}_{18} \mathrm{O}$ & 154.21 & Isobornyl alcohol \\
\hline 2 & 19.024 & 2.773 & $\mathrm{C}_{12} \mathrm{H}_{16} \mathrm{O}_{3}$ & 208.10 & Asarone \\
\hline 3 & 24.291 & 2.413 & $\mathrm{C}_{19} \mathrm{H}_{28} \mathrm{O}_{4}$ & 320.19 & Phthalic acid \\
\hline 4 & 25.406 & 1.288 & $\mathrm{C}_{17} \mathrm{H}_{34} \mathrm{O}_{2}$ & 270.25 & Palmitic acid \\
\hline 5 & 25.918 & 1.726 & $\mathrm{C}_{15} \mathrm{H}_{22} \mathrm{O}$ & 218.16 & naphthalenone \\
\hline 6 & 26.267 & 18.828 & $\mathrm{C}_{16} \mathrm{H}_{32} \mathrm{O}_{2}$ & 256.24 & n-Hexadecanoic acid \\
\hline 7 & 29.395 & 6.613 & $\mathrm{C}_{18} \mathrm{H}_{32} \mathrm{O}_{2}$ & 280.24 & 9,12 -Octadecadienoic acid (Z,Z)- \\
\hline 8 & 29.506 & 9.938 & $\mathrm{C}_{18} \mathrm{H}_{34} \mathrm{O}_{2}$ & 282.25 & trans-13-Octadecenoic acid \\
\hline 9 & 29.893 & 3.3860 & $\mathrm{C}_{18} \mathrm{H}_{36} \mathrm{O}_{2}$ & 289.13 & Octadecanoic acid \\
\hline 10 & 32.693 & 1.215 & $\mathrm{C}_{29} \mathrm{H}_{50} \mathrm{O}$ & 414.38 & $\gamma$-Sitosterol \\
\hline 11 & 33.458 & 4.181 & $\mathrm{C}_{18} \mathrm{H}_{36} \mathrm{O}_{2}$ & 284.27 & Dihydrolycorine \\
\hline
\end{tabular}

acid, Linolelaidic acid, cis-13-Octadecenoic acid, Octadecane, 3-ethyl-5-(2-ethylbutyl)-, Methyl stearate, 9,12-Octadecadienoic acid (Z,Z)-, trans-13-Octadecenoic acid, Octadecanoic acid, 8-Pregnene, 3-acetoxy-20-hydroxymethyl-4,4,14-trimethyl, Methyl octadec6,9-dien-12-ynoate, $\beta$-Sitosterol, $\gamma$-Sitosterol, Dihydrolycorine, 3,19:14,15-Diepoxypregnan-20-one, 3,11,18-triacetoxy-, 3Betaacetoxy-6-nitroandrost-5-en-17-one, Labda-8(20),12,14-trien-19oic acid, methyl ester, Isobornyl 3-methylbutanoate, Terephthalic acid, bis(2-ethylhexyl)ester, Squalene, 9-Desoxy-9x-chloroingol 3,7,8,12-tetraacetate, psi-Cholesterol, Tocopherol, Campesterol, Stigmasterol.

\section{Antioxidant activity}

The free radical scavenging activity was determined by DPPH assay activity. The activities were analysed statistically by graph pad prism and the IC50 value was calculated. Of all the four formulations, formulation B showed better Antioxidant property on a comparative note. The formulation was evident to have rich in flavonoids and phenolic compounds which have direct inhibitory activity on the free radical mechanism and hence mitigates the Antioxidant nature thereby ceasing the oxidation. The effect free radical scavenging activity was depicted in Figure 2.

\section{Antibacterial activity}

The bacterial strains Staphylococcus aureus $(9 \mathrm{~mm})$ and Bacillus cereus $(11 \mathrm{~mm})$ and Escherichia coli $(7 \mathrm{~mm})$ and Klebsiella pneumonia (9 $\mathrm{mm}$ ) showed zone of inhibition i.e., the MIC values were found to be 5.0 $\mu \mathrm{g} \mathrm{mL}-1$ for gram positive and 5.0 and $2.5 \mu \mathrm{g} \mathrm{mL}-1$ for gram negative bacteria respectively and were shown in Figure 5. For the determination of the antibacterial activity of the plant extracts it is evident that the disk 
diffusion method could not be persistently reliable method and hence it was performed by agar dilution method where the anti-bacterial activity was shown at the lower concentration on a comparative note. The evaluation of the present study includes disk diffusion, broth dilution assay and broth microdilution assay and was depicted in Figure 6 and 7 . Where the broth microdilution assay was performed using resarzurin to enhance the detection of the bacterial growth. The extent of bacterial activity was determined based on the intensity of colour i.e., the blue coloured fluorescence indicated the effect of anti-bacterial nature of the sample whereas the pink indicates mild to moderate activity. The MIC values were found to be 0.390 and $0.781 \mu \mathrm{g} \mathrm{mL}-1$ for the gram positive stains i.e., Staphylococcus aureus and Bacillus cereus and the 6.250 and $3.125 \mu \mathrm{g} \mathrm{mL}-1$ gram negative bacteria i.e., Escherichia coli and Klebsiella pneumonia respectively and showed better quantitative determination of the bacterial activity than disk diffusion method and broth dilution assay were shown in Table 5 .

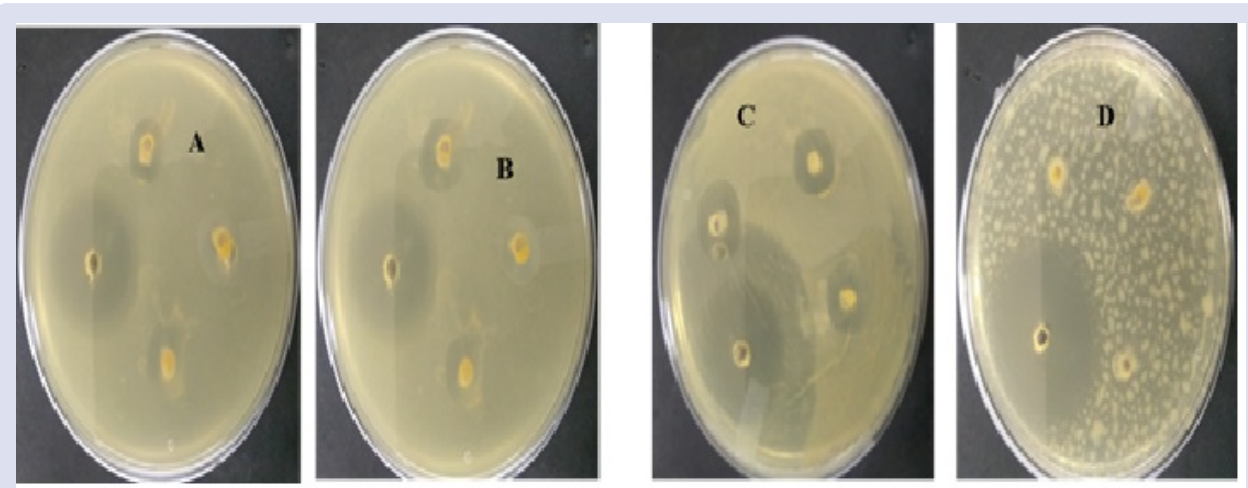

Figure 5: Disk Diffusion method for Gram Positive Staphylococcus aureus (A), Bacillus cereus (B) and Gram Negative Escherichia coli (C), Klebsiella pneumonia (D) at $2.5,5$ and $10 \mu \mathrm{g} \mathrm{mL}^{-1}$ concentration.
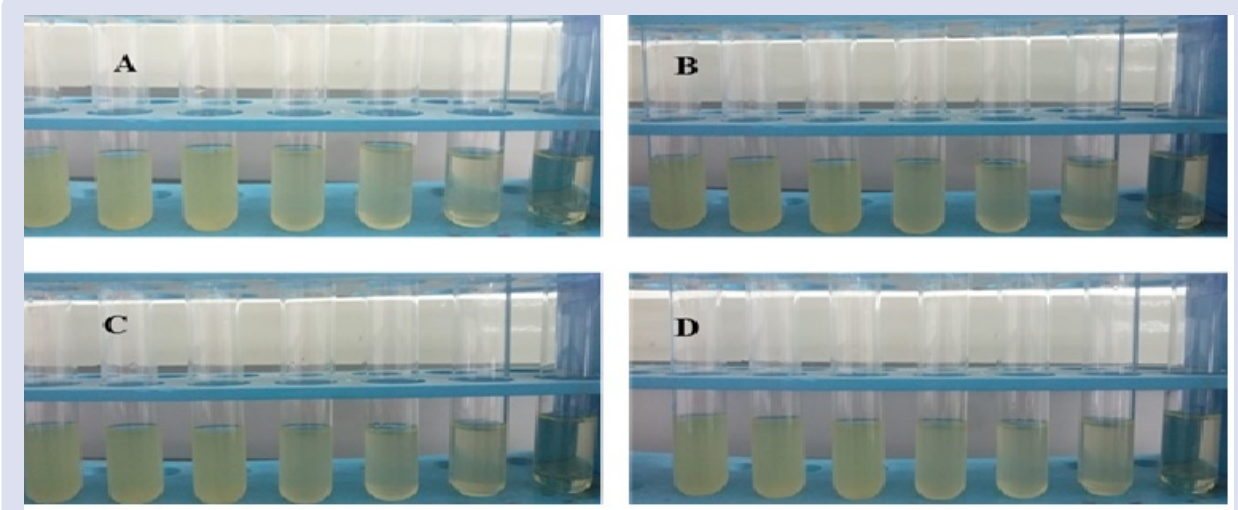

Figure 6: Broth Dilution Assay method for Gram Positive Staphylococcus aureus (A), Bacillus cereus (B) and Gram-Negative Escherichia coli (C), Klebsiella pneumonia (D) at $10 \mathrm{mg} \mathrm{mL}^{-1}$ to $0.15625 \mathrm{mg} \mathrm{mL}^{-1}$ concentration.

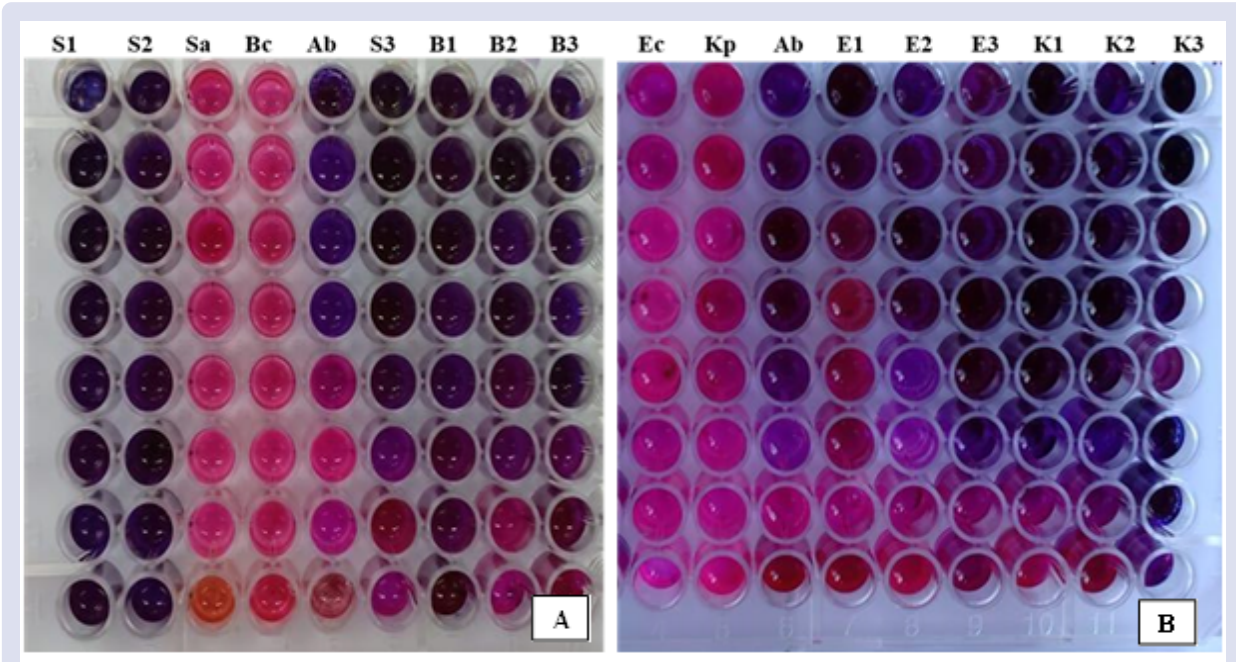

Figure 7: Broth Microdilution Assay method for Gram Positive Staphylococcus aureus, Bacillus cereus (A) and Gram Negative Escherichia coli, Klebsiella pneumonia (B) at $10 \mathrm{mg} \mathrm{mL}^{-1}$ to $0.07812 \mathrm{mg} \mathrm{mL}^{-1}$ concentration (each in triplicate). 
Table 5: Minimum inhibitory concentrations of MMV against gram positive and gram-negative stains.

\begin{tabular}{ccccc}
\hline \multirow{2}{*}{ Type of assay } & \multicolumn{4}{c}{ Growth Medium $\left(\mathbf{u g ~} \mathrm{mL}^{-1}\right)$} \\
\cline { 2 - 5 } & Bacillus cereus & Staphylococcus aureus & Escherichia coli & Klebsiella pneumonia \\
\cline { 2 - 6 } & 5.0 & 5.0 & 5.0 & 2.5 \\
Disk Diffusion & 5.0 & 5.0 & 5.0 & 5.0 \\
Broth Dilution & 0.781 & 0.3906 & 1.562 & 0.781 \\
Broth Microdilution & &
\end{tabular}

\section{CONCLUSION}

To the best of our knowledge, the study provides the first HPLC-DADESI-MS and GC-MS analysis with antibacterial activity with the major primary and secondary metabolites. The phytochemical analysis proves the formulation B contains major bioactive constituents. The elemental analysis inferred the presence of heavy and the trace elements were found to be in lesser quantity in formulation $\mathrm{B}$ on comparison with the others. The HPLC-DAD-ESI-MS analysis revealed the major amounts of alkaloids, flavonoids and the phenolic moiety in all the formulations. In relevance to the phytochemicals identified in HPLC-MS analysis the Antioxidant activity exerted was anticipated due to the presence of phenol and flavonoids .Based on this data, formulation B was selected for GC-MS analysis revealed the major bioactive compounds like asarone, pthalic acid, hexadecanoic acid and octadecanoic acid which are majorly mitigating the anti-bacterial activity. The presences of phytochemicals like $\alpha$ and $\beta$ asarone, $\gamma$-sitosterol, tocopherol may be responsible for the neuroprotective mechanisms. With this inference it was proved that the herbomineral formulation Manasamitra Vatakam showed anti-bacterial activity against both the gram positive and the gram negative stains.

\section{REFERENCES}

1. Duraisamy G, Manokaran K, Ganesan R, Kanakasabapathi D, Chandrasekar U. GC-MS analysis of bioactive compounds from the whole plant ethanolic extract of Evolvulus alsinoides. J Food SciTechnol. 2015;52(2):1212-7

2. Harshad K, Sathiyanarayanan L, Arulmozhi S, Kakasaheb M. Standardization, Chemical profiling, in vitro cytotoxic effects, in vivo anti-carcinogenic potential and biosafety profile of Indian propolis. J Ayurveda Integr Med. 2017;4:1-8

3. Hamburger M, Hostettman K. Bioactivity in Plants: The Link between Phytochemistry and Medicine. Phytochem. 1991;30(12):3864-74.

4. Khazdair MR, Anaeigoudari A, Hashemzehi M, Mohebbati R. Neuroprotective potency of some spice herbs, a literature review. J Tradit Complement Med. 2019;9(12):98-105.

5. Ahmad I, Aqil F, Owas M. In Turning Medicinal Plants in to Drugs. $1^{\text {st }}$ ed. Modern Phytomedicine. Wiley-Vch Verlag GmbH \& Co. KGaA, Weinheim; 2006.

6. Kishor P, Jigyasa P, Rabinarayan A. Ayurveda formulations: A roadmap to address the safety concerns. J Ayurveda Integr Med. 2018;8(4):279-82.

7. Frawley D, Lad V. How to prepare and use herbs according to Ayurveda. The Yoga of Herbs. $2^{\text {nd }}$ ed. Lotus Press; 2001.

8. Vidyanath R, Nishtewar K. Sashasrayogam; Vaidya Priya Vyakhyana. $2^{\text {nd }}$ ed. Velayudha Kuruche, Varanasi: Chowkhambha Sanskrit Series; 2008;354-55.

9. Srikalyani V, Ramasamy MK, Rajakanu R, Kumar RCS, Ilango K, Application of Chemometrics for the simultaneous estimation of stigmasterol and $\beta$-sitosterol in Manasamitra Vatakam-an ayurvedic herbomineral formulation using HPLC-PDA method. J App Pharm Sci. 2018;8(7):1-9.

10. Shaikh R, Pund M, Dawane A, lliyas S. Evaluation of anticancer, antioxidant, and possible anti-inflammatory properties of selected medicinal plants used in Indian traditional medication. J Tradit Complement Med. 2014;4(4):253-7.
11. Dinakaran SK, Sujiya B, Harani A. Profiling and determination of phenolic compounds in Indian marketed hepatoprotective polyherbal formulations and their comparative evaluation. J Ayurveda Integr Med. 2018;9(1):3-12.

12. Chauhan A, Goyal MK, Chauhan P. GC-MS technique and its analytical applications in science and technology. J Anal Bioanal Tech. 2014;5(6):1-5.

13. Vellingiri V, Ravichandrana N, Rajalakshmia P, Brindhaa P, Aravamudhan G, Kumaravelub C. Microscopic, phytochemical, HPTLC, GC-MS and NIRS methods to differentiate herbal adulterants: Pepper and papaya seeds. J Herbal Medicine. 2018;11:36-45

14. Anja K, Piskernik S, Barbara J, Sonja SM. Evaluation of diffusion and dilution methods to determine the antibacterial activity of plant extracts. J. Microbiol. Methods. 2010;81(2):121-6.

15. Changtai Z, Chunlei D, Yinze K, Lingxia L, Qingsi W, Yuyou. Microdilution inhibition test of Chinese herbs to assess their effect against clinical strains of Ureaplasma urealyticum in vitro. J Nanjing Med Univ. 2009;23(2):143-5.

16. Zhang Q, Zhang J, Shen J, Silva A, Dennis DA, Barrow CJ. A Simple 96-Well Micro Plate Method for Estimation of Total Polyphenol Content in Seaweeds. J Appl Phycol. 2006;18(3):445-50.

17. Herald TJ, Gadgil P, Tilley M. High-Throughput Micro Plate Assays for Screening Flavonoid Content and DPPH-Scavenging Activity in Sorghum Bran and Flour. J Sci Food Agri. 2012;92(11):2326-31.

18. Kim E, Goldberg M. Serum Cholesterol Assay using a Stable LibermannBurchard Reagent. Clin Chem. 1969;15(12):1171-9.

19. Xu BJ, Chang SKC. Phytochemical Profiles and Health-Promoting Effects of Cool-Season Food Legumes as Influenced by Thermal Processing. J Agri Food Chem. 2009;57(22):10718-31.

20. Ni QX, Xu GZ, Wang ZQ, Gao QX, Wang S, Zhang YZ. Seasonal Variations of the Antioxidant Composition in Ground Bamboo Sarasa argenteastriatus Leaves. Int J Mol Sci. 2012;13(2):2249-62.

21. Mfengwana PMAH, Mashele SS, Manduna IT. In vitro Antibacterial, Antioxidant and Anti-Inflammatory Effects of Senecio asperulus and Gunnera perpensa from Mohale's Hoek, Lesotho. Pharmacog J. 2019;11(4):730-9.

22. Subramanian R, Gayathri S, Rathnavel C, Raj V. Analysis of mineral and heavy metal levels nutrients in medicinal plants collected from local market. Asian Pac J Trop Biomed. 2012;2(1):74-8.

23. US EPA O. SW-846 Test Method 3052: Microwave assisted acid digestion of siliceous and organically based matrices. 1996;32:3628-32.

24. Zhao L, Huang C, Shan Z, Xiang B, Mei L. Fingerprint analysis of Psoralea corylifolia L. by HPLC and LC-MS. J Chromatogr B. 2005;821(1):67-74

25. Zhen yaY, Dan-yi L, Shun Y, Zhang RR, Jiang ZJ, Zhi-guo M. Chemical fingerprint and quantitative analysis of cistanche deserticola by HPLC-DAD-ESI-MS. J Food Drug Anal. 2013;21(1):50-7.

26. Septaningsih DA, Darusman LK, Afendi FM, Heryanto R. Liquid chromatography mass spectrometry (LC-MS) fingerprint combined with chemometrics for identification of metabolites content and biological activities of curcuma aeruginosa. Indones J Chem. 2018;18(1):43-52.

27. Ezhilan BP, Neelamegam R. GC-MS analysis of phytocomponents in the ethanol extract of Polygonum chinense L. Phcog Res. 2012;4(1):11-4.

28. Ponnuchamy K, Singaravelu S, Munisamy G. GC-MS profiling and antibacterial activity of Sargassum tenerrimum. J Pharma Research. 2013;6(1):88-92.

29. Ahmad S, Hassan A, Rehman T, Basit A, Tahir A, Adeel AM. In vitro Bioactivity of extracts from seeds of Cassia absus L. growing in Pakistan. J Herbal Med. 2019. 


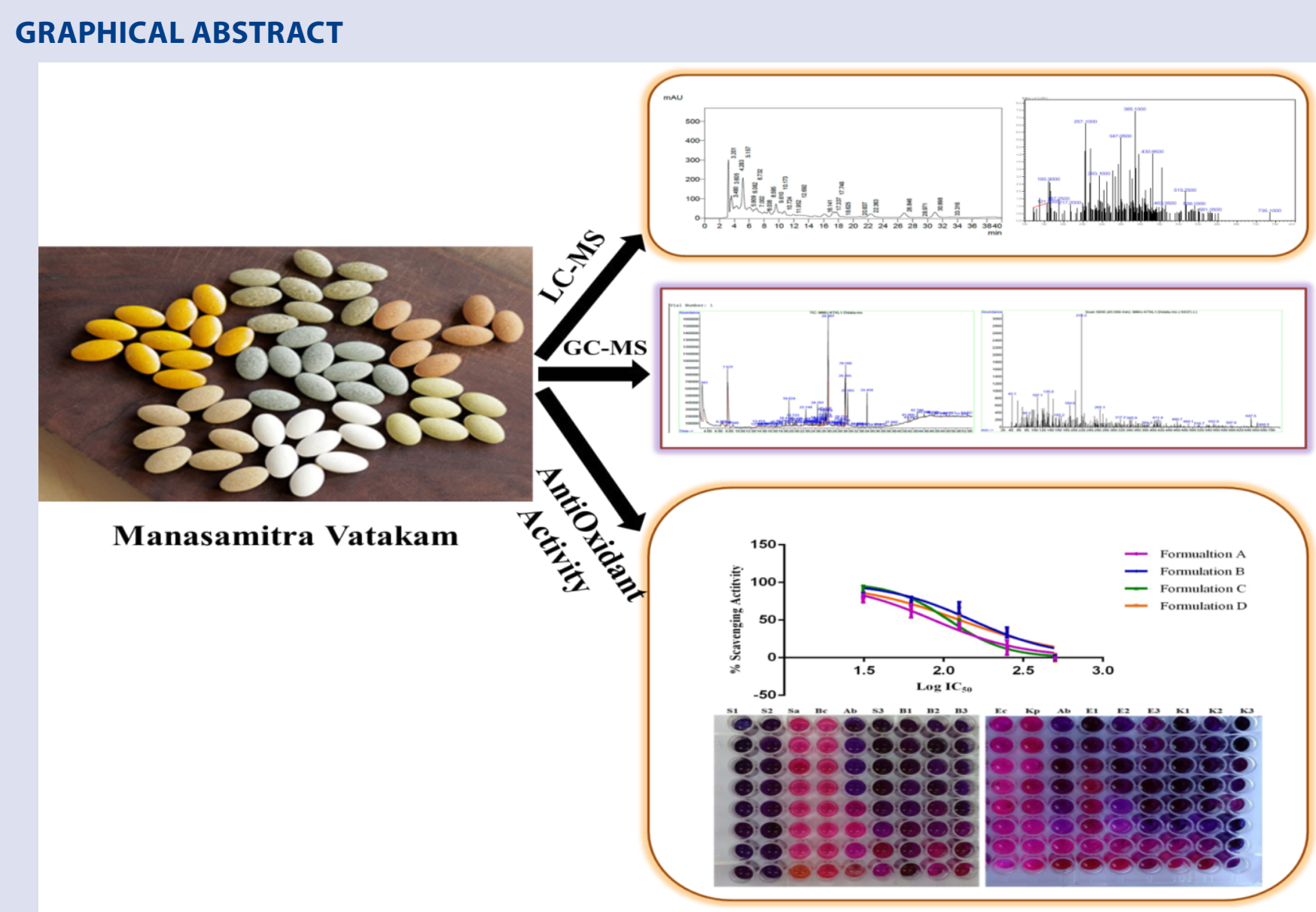

\section{ABOUT AUTHORS}

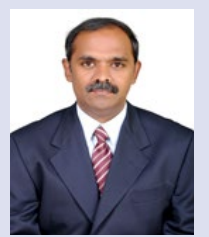

Dr. K. Ilango received his Ph.D in Faculty of Pharmacy from Sri Ramachandra Institute Higher education \& Research, Chennai and his Master's degree from Birla Institute of Technology and Science (BITS), Pilani, Rajasthan. Dr. K. Ilango has been an active Academic Professional in several reputed Institutions. His academic journey in SRM began in 1994. Since then, Dr. K. Ilango's involvement in academics had been remarkable, Starting from his service as Head the Department of Pharmaceutical Chemistry, SRM College of Pharmacy, to leading dual roles as Vice-Principal cum Prof \& Head of the Department of Pharmaceutical Chemistry and as Dean for Interdisciplinary Institute of Indian System of Medicine (IIISM) SRM University, his contribution and sharing of knowledge has benefited several aspiring students.

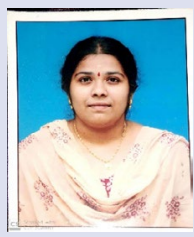

Srikalyani V has completed her Master's degree from KVSR Siddhartha college of Pharmacy, AP in the department of pharmaceutical analysis. Since then she is doing Ph.D under the guidance of Dr.K.Ilango.

Cite this article: Srikalyani V, Ilango K. Chemical Fingerprint by HPLC-DAD-ESI-MS, GC-MS Analysis and Anti-Oxidant Activity of Manasamitra Vatakam: A Herbomineral Formulation. Pharmacog J. 2020;12(1):115-23. 